\title{
Workplace-Oriented Research and Mentoring of Entreprenuers: Cooperation University-Industry
}

\author{
Ileana Hamburg \\ Institut Arbeit und Technik, WH Gelsenkirchen, \\ University Limerick, Ireland, IPA Craiova, Romania \\ Emma 0'Brien \\ Institut Arbeit und Technik, WH Gelsenkirchen, \\ University Limerick, Ireland, IPA Craiova, Romania \\ Gabriel Vladut \\ Institut Arbeit und Technik, WH Gelsenkirchen, \\ University Limerick, Ireland, IPA Craiova, Romania
}

\begin{abstract}
The benefits and longer impact of a strong cooperation university-industry particularly for entrepreneurs and small and medium-sized enterprises - SMEs - are known from different studies but it seems that measures in order to strength it are not sufficient. This paper explores the innovation barriers faced by small companies, challenges they face when collaborating with universities and explores if workplace research skills can potentially offer a method to enhance the absorptive capacity of small companies. Some forms of mentoring for entrepreneurs, a definition of the relationship mentormentee are shortly presented. Example of projects with the participation of the authors and measures which are planned to be implemented to to improve cooperation university-industry are also given.
\end{abstract}

\section{INTRODUCTION}

Small and medium-sized enterprises - SMEs are the dominant form of business organisations in the EU; more than $99 \%$ of enterprises in the European Union are SMEs. SMEs greatly contribute to employment and wealth in Europe: accounting for nearly $70 \%$ of European private service jobs. In Europe, the number of those employed by SMEs is high, particularly in sectors such as construction, metal products and the wood and furniture related industries. SMEs generate large portions of wealth in the EU (2013).

The new economy brings with it many challenges for SMEs. There is an EU average birth rate of $10 \%$ for small companies, however their growth rate remains quite low, at 2\%. Despite SMEs being more productive than larger organisations, they often remain stagnant. (Eurostat, 2015) In many cases SME owner/managers are concerned about the survival of the firm and find it difficult to plan forward (Garland et al, 1984). Furthermore, in a recent project Archimedes, SMEs identified the burden of workload on them trying to sustain a business and the need for staff to take initiative and seek new ideas. (O'Brien and Hamburg, 2014). Therefore, it is important for SMEs to develop entrepreneurship to support SME owners in growing the company.

It is therefore important to encourage SMEs to absorb new and external knowledge for faster innovation (Hamburg and O'Brien, 2014). The importance of knowledge transfer is recognised by EU28 members and is reflected in their national programmes developed under the Lisbon strategy. 
Efforts to support public research institutions to improve this situation have been done within the Committee for Scientific and Technical Research (CREST).

University-industry cooperation is associated with the transfer of knowledge and technology, this collaboration is important because helps companies to become more competitive To ensure that the achievements of the academic sector also benefit industry, and in order to put academic research and knowledge to work specifically for industry it is necessary to strength their cooperation.

Many interactions between research institutions and companies involve large firms, being considered more durable and regular than with SMEs. Other reasons for this situation i.e. lack of interest from research and education institutions to support companies, poor capabilities of SMEs to recognise the importance of innovation for their businesses and competitiveness and to engage in knowledge transfer activities, existing of practical approaches that support research abut not the transfer of research results to SMEs.

In many countries the collaboration between research (knowledge producers) done i.e. in universities and industry (knowledge users) facilitating knowledge transfer is underdeveloped particularly referring SMEs. This has a negative impact on the innovation and competitiveness of SMEs and finally on the sustainable growth of the corresponding countries.

One aspect where this cooperation is necessary and which is described in this paper is to learn entrepreneurs to do work-place oriented research.

Research skills will allow employees in the workplace to adapt to these changes by proactively seeking new opportunities for their company, making data driven decisions to implement these opportunities and evaluating the impact of this on the business performance. The entrepreneurs could learn i.e. to manage the implementation of a workplace research project by leveraging from internal resources readily available to them. They can to evaluate the value of the project whey work to their organisation from a financial, social and cultural perspective and identify future opportunities for their organisation.

Another aspect is that starting a company require for starting entrepreneurs to know many start-up programs and knowledge in many other domains (David and Hamburg, 2017). Very often SME employees need also help due to limited resources of the company. Mentoring is an instrument often used to support entrepreneurs who i.e. to enter a support program or receive venture capital. Mentoring activities can be divided into career-related and psychological activities (Kram 1983). Different forms of mentors can be used and experienced educators from universities can act as mentors. Some of them worked as entrepreneurs, other were partners in cooperation projects i.e. with SMEs.

This paper explores the innovation barriers faced by small companies, challenges they face when collaborating with universities and explores if workplace research skills can potentially offer a method to enhance the absorptive capacity of small companies. It presents aspects of university-industry collaboration (part 2) referring work -oriented research of entrepreneurs (part 3) and mentoring (part 4) with implementation within European projects (part 5).

\section{IMPORTANCE OF UNIVERSITY INDUSTRY COLLABORATION}

Innovation involves the utilisation of new knowledge or a new use or combination of existing knowledge. New knowledge may either be generated by the firm during its innovation 
activities (i.e. through intramural R\&D) or acquired externally through various channels (e.g. purchase of new technology). The use of new knowledge or the combination of existing knowledge requires innovative efforts that can be distinguished from standardised routines". (OECD, 2005)

Education providers have long been channels of this knowledge that can take the form of research partners, contract researchers, skills providers, informal interaction, technology transfer, equipment, resources and scientific publications. However, there are two main issues. Firstly, university industry collaborations are wrought with challenges such as trust, different incentives for conducting research, time constraints and project management issues (Cyert and Goodman, 1997; Plewa and Quester, 2006). To overcome these issues a phase of precollaboration was proposed by UK government's LINK programme in 2000. In addition, the innovation voucher scheme in Ireland and the Netherlands is focused on building precollaboration however often SMEs are not aware of such initiatives or do not have the time to search for relevant staff which are dispersed in different universities and research institutes nationally.

Secondly higher education produce 'general research' and an internal research capacity is required to allow them to adapt this research to their business (Soh and Subramanian, 2014). However, SMEs often do not have this internal research capacity due to limited resources. They therefore need to enhance their ability to leverage from external sources of knowledge such as that produced by universities. To do this it is important for them to develop an absorptive capacity. "Absorptive capacity is a dynamic capability which creates new firm resources by searching, acquiring, assimilating, transforming and exploiting external knowledge with internal resources" (Patterson and Ambrosini, 2015).

Studies have proven that the greater the internal research and development of the organisation the higher their ability is to collaborate and exploit external research conducted by higher educations (Bercovitz and Feldman, 2007; Fabrizio, 2009).

The lack of research on how to enhance a firm's absorptive capacity is evident. Lane, Koka, \& Pathak, 2006 argue that a combination of exploratory learning, transformative learning and exploitative learning is key. It requires individuals in companies to be continuously seeking and evaluating new research. Where ideas are sought it requires them to transform this knowledge into a format that can be exploited and used.

\section{WORK-PLACE ORIENTED RESEARCH}

Research skills empower the employee to identify and gather the most appropriate material to their learning needs, as a result it encourages a 'learning to learn approach'. The approach will allow employees to learn the skills to gather data in a systematic manner to fill knowledge gaps in their organisation. These skills can be applied to a wide variety of contexts, disciplines and professions.

It relates to EU policy on workplace learning and empowering workers (EU, 2010). Furthermore, it argues that in addition to absorptive capacity workplace research skills foster entrepreneurial mindset, they encourage inquiry based learning (Craig and Bielenberg, 2014) by promoting the exploration of new opportunities (ideas and opportunities), examining new ways of doing business, identify, implementing these using existing resources (into action), exploring how to use technology to deliver products/services (resources). These competencies align to the ENTRECOMP framework (Bacigalupo et al, 2016). 
Learning and teaching process of workplace oriented research skills focuses on critical thinking about business tasks in order to facilitate the recognition, acquisition and application of individual knowledge, skills and abilities, to achieve specific important outcomes for the learners, their work and the company. It includes a wide practice-based contribution to knowledge, approaches to learning and teaching giving the learner practice expertise with the teacher as facilitator with experience. When an HE coordinates the training or researcher, the cooperation with industry will be stronger. It is supposed that the employer contributes significantly to the content of the training programme including the nature of the practical oriented research project. The main motivations for employees undertaking such training are personal enthusiasm, the desire to develop oneself and to gain more professional expertise that contribute to improve business in company. It is not possible to gain a precise measurement of the economic value of such training to universities, researchers, employers and employees but it is sure that learning and employee development is a positive reward for staff and that such learning is more directly related to the employee's actual work than other training programs. The culmination of a work-based project in collaboration with HE enhances personal and professional confidence, aspirations and expertise. Enhanced personal expertise expressed mainly in terms of proven high-level intellectual skills, usually involving skills of synthesis, better judgement of levels of achievement and "seeing the broader picture" and ability to act as self-motivated learners (https://www.emeraldinsight.com/doi/full/10.1108/JWAM-10-2015-006 ). Direct impact on organisations or professional areas came from work activity contained within their small research projects that can made a real change to business in the company. Sure, the benefit to the employer is to get credentials

A key to learning research skills for their work is employees understanding of the learning methodology and supporting ICT tools. The position of the worker in company is important due the action involved in accessing data at workplace and then going on to develop and apply the research findings to a work-place oriented business project.

Work-place oriented research projects use the expertise of learning in HE, for example, research, evaluation, synthesis and critical thinking to enable practitioners to use the workplace and its resources for development and innovation.

\section{MENTORING}

Mentoring is in comparison with coaching/counselling a special form of active supporting of entrepreneurship competence, a "natural support" helping also young people with special needs to believe in themselves and boost her confidence. Mentoring helps the mentees to explore new ideas in a confidential ambiance, to look more closely at themselves, to reflect on opportunities and wishes.

Mentees meet with a trusted person to achieve i.e. entrepreneurial skills and/or enter into a work place quickly and to cope with initial problems to discuss and resolve emerging job problems of genuine nature and in relation to the individual needs, learn setting realistic goals and achieving them to acquire new skills and enhance their skills and thus their future career opportunities and prospects in the future through knowledge transfer from the mentor, build relationships or interactions allowing them to secure, maintain and advance in the job choosing a way that corresponds to the work routines and social actions of other employees. Mentors improve their personal fulfilment from investing in others, feel valued as a role model, gain a new appreciation, etc. 
Different forms of mentors for entrepreneurs can be tested. Peer mentoring usually takes place between an experienced person in a domain (mentor) and a person who is new in this context. Peer mentoring differs from classical mentoring first in fact that mentors and mentees are close in age, education level, etc. and that they are semi structured planned programs with specific guidelines and often with a number of activities and meetings in a determined time. In a formal mentoring approach, a mentee is paired with a mentor to help him or her to learn the ways of the business world. Most companies either have or are considering implementing a formal mentoring program in the near future. Often formal mentoring programs have specific goals, i.e. to transfer knowledge, advancing career goals, learning business management, or addressing performance deficiencies. But there are cases when the objectives are less structured and are determined by the mentor and mentee as the mentoring unfolds. In informal mentoring two people, whose chemistry is compatible, come together.

A mentoring relationship progresses through four stages (Kram 1983); initiation, cultivation, separation and redefinition. In the initiation phase the relationship between entrepreneur and mentor is established; in the cultivation phase mentoring activities take place. This stage is sometimes followed by the separation phase; the entrepreneur and the mentor finished the relationship. Very important is the redefinition phase where the mentor and entrepreneurs enter into a relationship in which they are equal. Kram mentioned that "the relationship ends entirely". In the process of mentoring entrepreneurs, the entrepreneurs should not be separated from the company (Van der Sijde et all, 2002) because supporting the career advancement of the entrepreneurs means the development of the company.

\section{METHODOLOGY}

In November 2016 a survey conducted by the consortium with 142 SMEs from Greece, Spain, Ireland, Germany, Romania and Lithuania regarding the barriers to innovation they face, challenges with collaborating with universities and research and how these could be overcome. A random sample of companies with between 1 and 250 employees were targeted. Of the responses $90 \%$ were from companies with less than 100 employees. Based on the results the authors started a new European cooperation university-industry within the Erasmus+ program.

\section{RESULTS}

Ninety seven percent of SMEs said they would like to be more innovative. The survey has illustrated that SMEs which are not in the initial stages of start-up or growth feel that they are currently not supported in terms of innovation. For them to become more innovative an extensive investment in such resources is required. However, it is difficult for the SME to identify the resources required to become more innovate also receiving a return on this investment can take time and create cashflow problems. SMEs due to their small scale have limited resources and in the survey cited time (48\%), money (49\%), equipment (60\%) and expertise (38\%) as barriers to innovation. Leveraging from external resources during periods where SMEs are facing innovation challenges can allow them to grow without having to make large initial investments until their business is sustained.

Universities have a huge body resources which SMEs can avail of, equipment and specialised knowledge is readily available. However, fifty one percent of SMEs work internally to address innovation challenges, only one third of SMEs approached higher education institutes. This expertise is often difficult to avail of, over $48 \%$ of companies felt that universities do not understand their business needs. As a result, research outputs and educational programmes are not contextualised to the needs of the company and the university. To adapt these a lot of time and effort is required on behalf of the company which is limited within SMEs. Further 
challenges in collaborating with HEIs were taking too long to implement ideas (41\%), lack of incentive $(25 \%)$ and cultural differences $(20 \%)$ In the survey many companies felt that HEIs were inaccessible to small companies for example "Scale of the projects will not get the support required i.e. too low on the ladder" and "We believe the company is too small to avail of substantial funding"

When queried regarding the internal research capacity of their companies, 52\% reported that they do not use research methods when innovating. Most SMEs (81\%) see research skills as important to make their company more innovative. Despite their importance $62 \%$ of SMEs do not have research skills. In general (54\%) SMEs highlighted that current educational programs do not provide the relevant research skills to assist them to conduct research.

\section{SOME PRACTICAL IMPLEMENTATIONS}

The authors started to work with industry within the Erasmus+ project Reinnovate which aims at providing employees in companies with workplace research skills to assist them to improve entrepreneurial competences by systematically seeking business opportunities, identifying initiatives and implementing these. With the increasing pace of change employees need to continuously adopt new technologies and methods of doing business to satisfy increasing customer demands. Research skills are a prime way of providing learners with the capacity to gather new knowledge to enable them to adopt these new methods. To reflect the use of research skills to allow learners to adapt to new business demands the programme title Smart Research as a 21st Century Skill for Business was agreed.

Research skills will allow employees in the workplace to adapt to these changes by proactively seeking new opportunities for their company, making data driven decisions to implement these opportunities and evaluating the impact of this on the business performance. The student will also be required to manage the implementation of the workplace research project by leveraging from internal resources readily available to them. They will have to evaluate the value of the project to their organisation from a financial, social and cultural perspective. They will also have to identify future opportunities for their organisation.

At the end of the programme the employee will have designed, managed and implemented a small-scale research project in their organisation, determined its impact on the organisation and explored future avenues for research. The programme will comprise of four modules which will align to the skills needs identified by SMEs in the needs analysis, skills needs identified in the literature and will map to the ENTRECOMP framework.

- Module 1: Using research to identify future opportunities

- Module2: Smart methods to gather and analyse data

- Module 3: Managing your research project

- Module 4: Evaluating success and future opportunities

The project will develop several different elements to allow the model to be put into practice.

\section{FUTURE ACTIVITIES}

Some activities to improve the cooperation university-industry are planned:

Firstly, a pedagogical framework for the delivery of workplace research skills using an inquiry based learning approach. It can be argued that this type of pedagogical approach facilities explorative learning by encouraging the learner to seek ideas and opportunities. It also enables transformative learning by encouraging the learner to contextualise such opportunities to the 
organisations needs and exploitive learning in that the learner applies the ideas to the business to allow them to be exploited.

The active and inquiry based learning approach stems from problem-based learning which was adopted by a previous project Archimedes (http://archimedes.ee/en/blog/erasmus-strategicpartnerships-education-ka2/). Problem Based Learning (PBL) is a form of inquiry-based learning, which in the Erasmus+ project Archimedes worked by the authors provided several benefits to SMEs like immediate return on investment, low cost, on the job training, thus the learning is highly contextualised and situated, practical and related to the SME's needs and sustains the organisation's competitive advantages (Hamburg and O'Brien, 20154. It encouraged innovation, both individual and cooperative work and thinking, a greater understanding of a topic due to active learning, engaging in the material. PBL increases motivation to learn thus developing a learning culture, developing skills in critical thinking, leadership, communication, problem solving.

Secondly, an ICT collaborative platform to facilitate inter organisational and collaborative research is in the development. This will enhance the university industry relationship by allowing both parties to work on research simultaneously building trust and collaboration by communicating results (Figure 1).
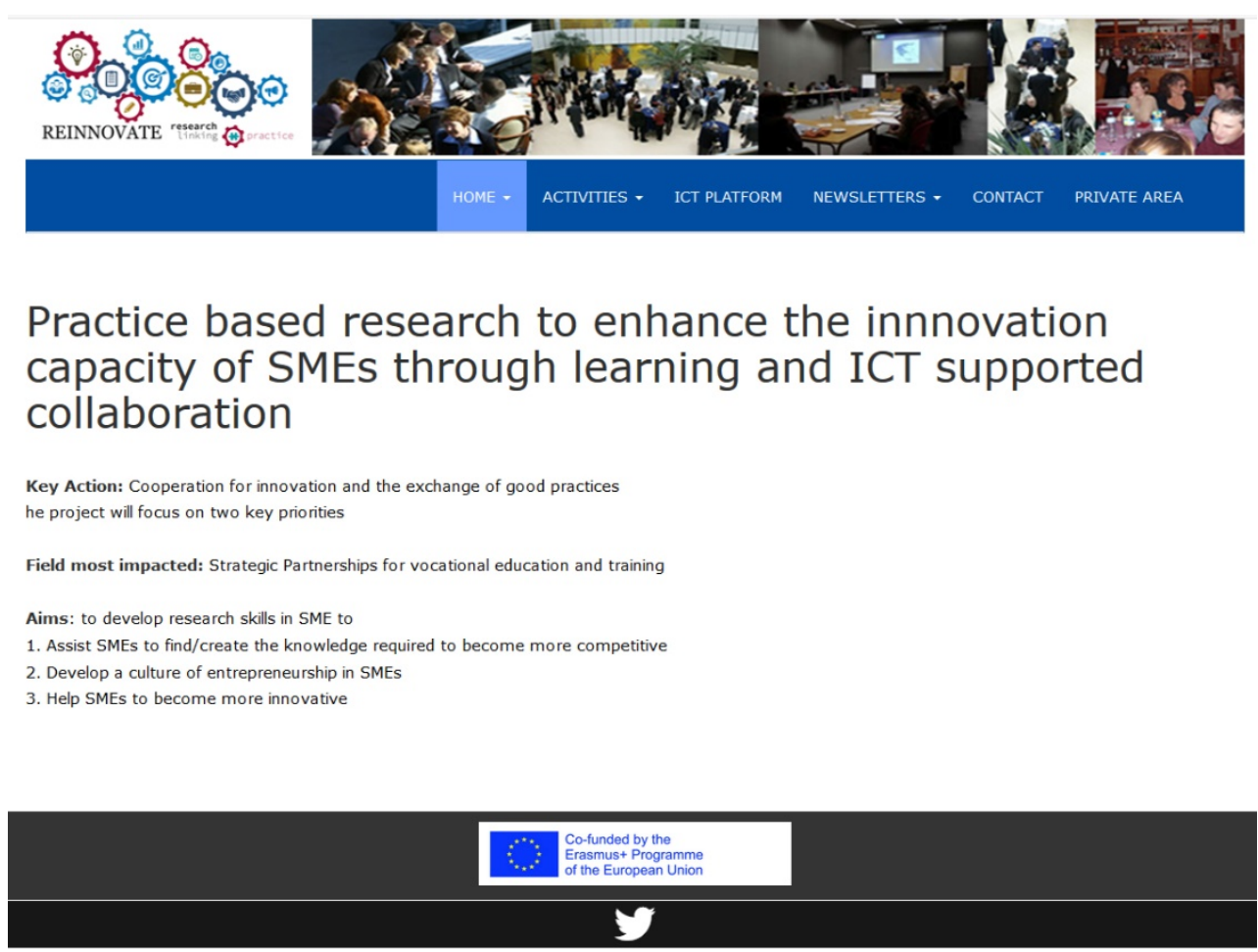

Figure 1: The Web site of the project connected with an ICT collaborative platform

Thirdly, a mentoring program for entrepreneurs online and face-to face started within Reinnovate with mentors from university and research, which collaborate within the project, and mentees entrepreneurs. Mentees should be taken from the SMEs, which are project partners, and from other companies within project partner countries: Ireland, Germany, Lithuania, Spain, and Romania.

The mentoring program aims particularly to develop workplace research skills of mentees which will enhance the absorptive capacity of SMEs by encouraging employees to source new ideas and opportunities and apply them to their organisation 
Fourthly, empirical research will be conducted to determine if the absorptive capacity of the organisation has been enhanced as well as the overall impact of research skills on the entrepreneurial culture and performance of the organisation.

Strengthening the "knowledge triangle", linking education, research, and innovation by providing a central hub where SMEs can provide the services and expertise offered by all universitiesin Europe. SMEs should be able to use an ICT platform to record the type of innovation they need. The centre can then refer them to the relevant HEI with the expertise to assist them. By recording the innovation needs of SMEs it can provide reports to academics on the innovation needs of SMEs and allow them to adapt their research to these needs, bridging the knowledge gap.

\section{References}

Bacigalupo, M., Kampylis, P., Punie, Y., Van den Brande, G., 2016. ENTRECOMP: The entrepreneurship competence framework. Luxembourg, Publication Office of the European Union.

Bercovitz, J.E., Feldman, M.P., 2007. Fishing upstream: Firm innovation strategy and university research alliances. Research Policy, 36(7), pp.930-948.

Craig, R., Bielenberg, B., 2015. Promoting a culture of inquiry: Foregrounding research skills in first and second year engineering students. QScience Proceedings, pp.14.

Cyert, R.M., Goodman, P.S., 1997. Creating effective university-industry alliances: An organizational learning perspective.

Davi, A., Hamburg, I. (eds.), 2017. Entrepreneurship and entrepreneurial skills in Europe: examples to improve potential entrepreneurial spirit. Opladen, Barbara Budrich.

European Commission, 2009. Communication from the Commission to the European Parliament, the Council, the European Economic and Social Committee and the Committee of the Regions - "Preparing for our future:

Developing a common strategy for key enabling technologies in the EU", Brussels.

European Commission, 2010. The Bruges Communiqué on enhanced European Cooperation in Vocational Education and Training for the period 2011-2020, Bruges, Belgium.

European Commission, 2013. Communication from the Commission to the European Parliament, the Council, the European Economic and Social Committee and the Committee of the Regions: EU Quality Framework for anticipation of change and restructuring.

EUROSTAT, 2015. Statistics on small and medium-sized enterprises Dependent and independent SMEs and large enterprises.

EUROSTAT, 2015. Statistics on small and medium-sized enterprises Dependent and independent SMEs and large enterprises.

Fabrizio, K.R., 2009. Absorptive capacity and the search for innovation. Research policy, 38(2), pp. 255-267.

Garland, J.W., Hoy, F., Boulton, W.R., Garand, J.C., 1984. Differentiating entrepreneurs from small business owners: a conceptualization. Academy of Management Review, 9(2), pp. 354-359.

Hamburg, I., O’Brien, E., 2014. Using strategic learning for achieving growth in SMEs. In: Journal of information technology and application in education.

Kram, K.E., 1983. Phases of the mentor relationship. Academy of Management Journal, 26 (4), pp. 608-625.

Lane, P. J., Koka, B. R., Pathak, S., 2006. The reification of absorptive capacity: A critical

O'Brien, E., Hamburg, I., 2014. Supporting sustainable strategies for SMEs through training, cooperation and mentoring. In: Higher education studies, 4(2), pp. 61-69.

OECD, 2005. Guidelines for Collecting and Interpreting Innovation Data, Third Edition.

Patterson, W., Ambrosini, V., 2015. Configuring absorptive capacity as a key process for research intensive firms. Technovation, 36, pp.77-89. 
Plewa, C., Quester, P., 2006. Satisfaction with university-industry relationships: the impact of commitment, trust and championship. International Journal of Technology Transfer and Commercialisation. 5(1-2), pp.79-101.

Van der Sijde, P.C., Ridder, A., Gomez, J.M., Pastor, J.T., Galliana, D., Mira, I., 2002. Infrastructures for spin-off companies. Elche, University of Miguel Hernandez.

\section{AKNOWLEDGMENT}

The paper describes the European Erasmus+ project Reinnovate. 